\title{
EL PROBLEMA DE LA FILOSOFÍA Y EL PODER EN D. DIDEROT
}

\author{
Arsenio GINZO FERNÁNDEZ \\ Universidad de Alcalá
}

La Filosofía ha pretendido, desde su nacimiento, contribuir a la articulación racional de la Ciudad. Prontamente hizo la experiencia de que no bastaba con ir desvelando las leyes ocultas de la Naturaleza, y con que el Universo físico apareciera dotado de una legalidad y una racionalidad que lo convirtieran en morada estable para el hombre, sino que surgía el imperativo ineludible de implantar la razón en aquel ámbito que se presentaba como creación humana, la vida política. Tarea particularmente dificil dado que no bastaba con una "reforma" del entendimiento mediante la que se operara el tránsito de la ignorancia al saber sino que era precisa además la reforma de la realidad misma de acuerdo con un proyecto racional, una realidad sobre la que incidían con prepotencia las pasiones e intereses de los individuos.

En este horizonte se establece un dificil, aunque hasta cierto punto insoslayable, diálogo entre el filósofo, como administrador del saber y de la Verdad, y los detentadores del Poder político. Se inicia así una dinámica cuya formulación paradigmática, desde la óptica filosófica, expresó Platón en su famosa carta VII: "No cesará en sus males el género humano hasta que los que son recta y verdaderamente filósofos ocupen los cargos públicos, o bien los que ejercen el Poder en los Estados lleguen, por especial favor divino, a ser filósofos en el auténtico

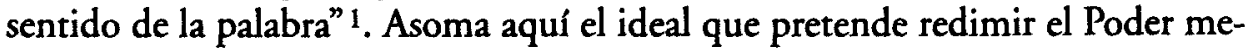
diante la Razón, implantar la Razón en la Ciudad. Ardua tarea en la que tan a menudo se va a tropezar a lo largo del decurso histórico con los consabidos tó-

1 Carta séptima, 326 b (versión de M. Toranzo).

ENDOXA: Series Filosfficas, $n .^{\circ} 10,1998, p p$. 251-280. UNED, Madrid 
picos del candor y la ingenuidad del intelectual, por un lado, y el cinismo de los detentadores del poder por otro. La propia experiencia siracusana de Platón constituye un caso bien significativo de tal situación. Quizá el último gran representante de esta peripecia lo constituya un pensador de la envergadura de Heidegger. En sus veleidades políticas también parece haber abrigado la ilusión de haber querido conducir (führen) al Jefe (Führer) en un momento en que se pretendía reconducir el rumbo de la civilización occidental 2 . También Heidegger, después de su breve experiencia como rector de la Universidad de Friburgo, tuvo que escuchar el viejo reproche: “¿De retorno de Siracusa?” 3 . Pero esta larga historia, que podemos circunscribir al período que va desde Platón hasta Heidegger, pasa por muchos capítulos, de índole y desarrollo desiguales. Por otra parte no es sólo el representante del saber quien se esfuerza por encauzar el ejercicio del Poder. También desde este último se busca a menudo la sanción del saber, tratando de alcanzar un determinado nivel de comprensión y legitimidad. A este respecto también el saber viene a constituir una forma de Poder.

No cabe duda que uno de los capítulos más significativos de este prolongado diálogo está constituido por el Siglo de las Luces, profundamente polarizado por la temática tanto filosófica como política. En el horizonte del movimiento ilustrado, Diderot aparece como uno de sus representantes más cualificados, aun cuando no fuera un pensador eminentemente político como Montesquieu y Rousseau. En las páginas siguientes vamos a intentar aproximarnos a su visión del problema Filosofía-Poder dentro del movimiento general de ideas que caracteriza a su siglo.

\section{Filosofía y Poder en la Ilustración. Diderot y el movimiento ilustrado}

La filosofía de la Ilustración, en cuanto filosofía militante, vuelta hacia el mundo, se muestra profundamente preocupada por la Ciudad. No se trata en realidad de una preocupación más sino de algo inseparable de su vocación intelectual. Según va avanzando el siglo, va resultando cada vez más perceptible

2 O. Poggeler, "Den Führer führen? Heidegger und kein Ende», en Philosophische Rundschau 32 (1985), 26 ss.

3 J. Altwegg (ed.), Die Heidegger Kontroverse, Frankfurt a. M., 1988, 176 ss. 
la vocación política del filósofo ilustradón. Entre el Diccionario histórico y critico de P. Bayle y la Enciclopedia se sitúa precisamente el emblemático opúsculo de Dumarsais El Filosofo, que después habrá de ser retomado por Diderot en la Enciclopedia. Nos encontramos sin duda ante uno de los manifiestos más representativos de la Ilustración, la época de la "filosofía", en su acepción cósmica mundana. En efecto el filósofo de que aquí se trata no vive encerrado en una torre de marfil, ni es tampoco un misántropo, ajeno a los avatares mundanos. Por el contrario, el filósofo ilustrado, reconciliado con los imperativos de la naturaleza humana, vive profundamente abierto a la sociedad y se encuentra en su elemento en la interacción con los demás seres humanos, reiterando con Terencio aquello de homo sum, humani a me nibil alienum puto. Se reafirma así la vocación profundamente humanista de la filosofía de la Ilustración. Para este tipo de filosofo "la sociedad civil vendría a constituir, por así decirlo, una especie de divinidad sobre la tierra" 5 . Nos encontramos de este modo en un horizonte propicio para plantear las relaciones con el Poder. No en vano el mencionado artículo sobre el "filósofo" acaba evocando el viejo sueño de la convergencia entre Filosofía y el Poder: "Unid un soberano con un filósofo de esta índole y tendréis un soberano perfecto". He aquí la confesión abierta del suefio secreto que recorre la Ilustración, he aquí una de sus utopías más peculiares.

Se ha podido afirmar que todo filósofo ilustrado ha sentido una vocación, directa $o$ indirecta, de aconsejar al Príncipe, al soberano ${ }^{6}$. Los libros de los filósofos "forman a los Príncipes", escribía con satisfacción Voltaire. Ciertamente no se trataba de una novedad absoluta, pues, aparte de los conocidos modelos clásicos, la Edad Media había proseguido a su manera esa vocación mediante la confección de sus característicos "espejos de príncipes" y la propia Edad Moderna se había pronunciado tempranamente, aunque con talante dispar, acerca de esta cuestión, a través de El Principe de Maquiavelo y la Educación del príncipe cristiano de Erasmo. Lo peculiar de la Ilustración reside más bien en la intensidad y profusión de este tipo de planteamientos bien a través de los escritos de los ilustrados bien a través de sus actitudes prácticas. El con-

4 Cfr. Ch. G. STRICKLEN, "The philosophe's political mission: the creation of an idea, 1750-1789", en Studies on Voltaire, 86 (1971), 137 ss. ; R. ReICHARDT y E. SCHIMTT (eds.), Handbuch politisch -socialer Grundbegriffe in Frankreich 1680-1820, Oldenburg, München, 1985, art. "Philosophe, Philosophie", 7 ss.

5 Encyclopedie, XII, art. "Philosophe", 510.

6 J. M. Goulemot, "Despotisme eclaire?", en P. ORY (ed.), Nouvelle histoire des idées politiques, Paris, 1987, 74. 
vencimiento de vivir en el "siglo de la Filosofía" llevaba aparejada la aspiración a implantar la razón en el mundo de la vida, más allá de la conciencia subjetiva del filósofo. Esta tendencia generalizada de la época se veía corroborada por el temprano magisterio político ejercido por un autor como Montesquieu. A la altura de 1756 ya puede escribir Grimm a este respecto: "La obra El espíritu de Las leyes... ha operado una revolución plena en el espíritu de la nación. Las mejores cabezas se han vuelto, desde hace siete u ocho años, hacia estos objetos importantes y útiles. Los asuntos de gobierno se convierten de una forma creciente en una materia de filosofía y de discusiones" 7 . En este horizonte cabría destacar la intervención de Diderot ante Catalina II, la de Voltaire, d'Alembert y Helvetius ante Federico II, las reflexiones de Rousseau destinadas a los corsos y a los polacos y, por último, a Condorcet, que, metido ya en el torbellino revolucionario, hablaba de la necesidad de llevar a cabo la "unión de la filosofía con la política", conduciendo la filosofía a la política, o más bien "confundiéndolas". En esto había consistido una de las aspiraciones fundamentales de su siglo, al menos en varios de sus representantes cualificados.

Una figura cronológicamente tan cercana a los ilustrados como es Bossuet también habia a fondo la problemática de "formar" al Príncipe, pero las coordenadas son bien distintas. Sirviéndonos de una acertada expresión de J. Proust, cabría decir que Bossuet se mueve todavía en el horizonte del "triángulo sagrado" formado por el Sacerdote, el Príncipe, y la presunta voluntad de la Divinidad. Los ilustrados, y con ellos Diderot, consideran que ha llegado el momento de cambiar de paradigma ${ }^{8}$. Ahora el triángulo conceptual habría de estar compuesto idealmente por el Filósofo, el Príncipe y la Voluntad general. En el proceso de secularización emprendido por la ilustración, asistimos a un relevo en la administración de la Verdad y en la dispensación de legitimidades. Surge así, tal como se ha indicado a menudo, una especie de sacerdocio laico, de nuevos directores de conciencia. Un marcado proceso de secularización suponía e implicaba el mencionado relevo en la dirección de las conciencias. Se articulaba así una característica figura del intelectual europeo, del que en nuestro siglo un J. P. Sartre y un B. Russell suponen todavía una encarnación prototípica.

En ambos triángulos subsiste la figura del Príncipe. Los ilustrados, incluso en el seno de la tradición materialista, como es el caso de d'Holbach, se mues-

7 J. M. Dolle, Diderot. Politique et éducation, París, 1973, 34.

8 J. Proust, «Diderot et l'experience russe: un exemple de pratique théorique au XVIII siècle», en Studies on Voltaire 154 (1976), 1977 ss. 
tran refractarios a la idea de republicanismo, sobre todo para un país de la envergadura de Francia. Pero al cambiar los otros dos elementos del triángulo, también tenía que cambiar el papel desempeñado por el Príncipe. Así, el derecho divino se transmuta, con más o menos decisión, en una especie de contrato entre el soberano y los súbditos, a la luz del moderno iusnaturalismo con el que conectan los ilustrados. Así lo afirma sin rodeos el propio Diderot: "El consenso de los hombres reunidos en sociedad es el fundamento del Poder"9. Ello implicaba a la vez la sustitución del magisterio del sacerdote por el del filósofo que, como queda apuntado, se sentía investido de una misión histórica, de un alto magisterio moral e intelectual, como un nuevo tipo de sacerdocio en el que no faltaban nuevos dogmas y espejismos. Rousseau, en lucha contra sus antiguos compañeros de la República de las letras, supo ver lúcidamente este problema. No deja de ser significativo a este respecto que Voltaire, como jefe de filas del movimiento ilustrado, acepte ser considerado como una especie de patriarca de la "iglesia de los sabios" que constituiría la intelligentsia ilustrada, y a la que, en lucha contra el reino de los prejuicios, los errores y las supersticiones estaría prometido un "reino" en el que por fin imperaría la razón. Por supuesto Diderot, aunque no le gustara tanto esta terminología como a Voltaire, estaría destinado a ser uno de los grandes dignatarios de esta nueva "iglesia".

Pero sin que quepa aquí insistir ulteriormente sobre este punto, no cabe duda que uno de los combates centrales del Siglo de las Luces gira en torno a las instancias legitimadoras del Poder político, al conflicto entre la visión ilustrada y la tradicionalista que seguía insistiendo en la sanción teológica del Antiguo Régimen. La Religion, l'Etat et les bonnes moeurs constituían el lema acariciado por los adversarios de las Luces ${ }^{10}$. En última instancia, la Religión y el Estado constituyen un binomio inseparable que ha de ser defendido con toda decisión contra las tendencias subversivas de los ilustrados. Así lo hace una publicación tan significativa como el Journal de Trévoux con su defensa de la monarquía absoluta y de la alianza tradicional entre la Iglesia y el Estado. De una forma algo más matizada se pronunciaba $L$ 'année litteraire, pero en cualquier caso el enfoque tradicionalista seguía siendo el dominante, la religión la sanción última del poder político. Se entabla así toda una lucha por la conquista de la instancia ideológica que legitimara el Poder. La religión tradicional se les presentaba a los

9 D. Diderot, Escritos políticos (Estudio preliminar, traducción y notas de A. Hermosa Andújar), Madrid, 1989, 20.

10 R. SORIANO, La Ilustración y sus enemigos, Madrid, 1988, 12. 
ilustrados como la sanción última de todo el universo ideológico del Antiguo Régimen. De ahí la intensidad del conflicto entre ambos polos. El propio Diderot ha descrito con toda claridad esta situación cuando le escribe a la princesa Dashkoff: "El primer ataque contra la superstición ha sido violento, desmesurado. Una vez que los hombres han osado de alguna manera asaltar la barrera de la religión, la más formidable que existe en cuanto la más respetada, resulta imposible detenerse" 11.

Sumidos en esta dinámica, los ilustrados se veían implicados en la confrontación teológico-política que giraba en torno al Antiguo Régimen. Si para los adversarios de las Luces, las perturbaciones de los Estados, el "tambaleamiento de los tronos" y el "desmoronamiento de los altares" provendrían de la crítica frívola y subversiva de los filósofos, los ilustrados, por el contrario, con su insistencia en la racionalidad y la tolerancia tratan de mostrar que en última instancia lo que intentan es asentar el Poder sobre unas bases más sólidas: ¿qué filósofo, se pregunta $\mathrm{D}$. de Sales, ha ensangrentado los tronos y armado los hombres contra los hombres?.. Haced sentarse al filosofo al pie de los tronos y no veréis estos grandes crímenes" 12 . Se recuerda por el contrario que el fanatismo religioso ha provocado innumerables víctimas a lo largo de la historia.

Los ilustrados se enfrentaban abiertamente al status quo político-religioso imperante, a la autoridad establecida, pero "sólo ellos tenían la autoridad moral" escribirá Tocqueville en su mirada retrospectiva sobre el Antiguo Régimen. Eran conscientes de que a pesar de su marginación, e incluso persecución, el movimiento ilustrado también suponía una forma peculiar de Poder, de autoridad. Este nuevo Poder estaba corroborado por el ascendiente cada vez mayor sobre la opinión pública. Gritan contra los filósofos, sefiala Voltaire, y sin duda tienen razón al hacerlo pues si la opinión pública viene a ser la reina del mundo, "los filósofos gobiernan a esta reina". A pesar de todas las frustraciones, y también de los espejismos sufridos, el paso del tiempo parecía confirmar el control creciente sobre la reina del mundo a que se refería Voltaire. A pesar de sus decepciones, Diderot no dudaba en seguir afirmando enfáticamente, hacia finales de su vida, en su Ensayo sobre los reinados de Claudio y Nerón, toda la relevancia que a sus ojos revestía el magisterio filosófico: "El Magistrado administra la justicia, el Filósofo enseña al Magistrado qué es lo justo y lo injusto. El

11 D. Diderot, Oeuvres complétes, de J. Assézat y M. Tourneux, XX, 28. (salvo indicación en contrario, citaremos conforme a esta edición. En adelante: O.C.).

12 Cfr. R. ReIChardt y E. Schmitt, op. cit., 31. 
Militar defiende la patria; el Filósofo enseña al Militar lo que es la Patria... El Soberano los gobierna a todos; el Filósofo enseña al Soberano cuál es el origen y el límite de su autoridad. Cada hombre tiene deberes que cumplir en su familia y en la sociedad; el Filósofo enseña a todos cuáles son estos deberes" 13 . He aquí ciertamente un texto paradigmático acerca de la autoconciencia de los ilustrados respecto a la universalidad de su magisterio. De ahí la consabida pasión por el problema de la educación que recorre todo el movimiento ilustrado, desde El espiritu de las leyes hasta las Memorias y el Informe sobre la instrucción pública que Condorcet redacta en pleno periodo revolucionario, pasando por supuesto por la Enciclopedia y las reflexiones de Diderot destinadas a Catalina II. Filosofia, Política y Educación constituyen sin duda una peculiar trinidad ilustrada. En última instancia, la educación posibilita la concreción del mensaje ilustrado, su vehículo hacia la sociedad. Mediante ella, los ilustrados intentan dirigirse a la vez al Poder que debe ponerse en sintonía con los tiempos históricos y contribuir con los medios que le son propios a implantar en la sociedad la nueva visión del mundo, y, por otro lado, al Pueblo al que hay que instruir acerca del conjunto de sus derechos y deberes. Diderot que aceptaba gustosamente el calificativo de "filósofo" hace suyo este doble cometido ilustrador, como testigo cualificado entre el Poder y el Pueblo, si bien sus posiciones se van a ir desplazando con el paso del tiempo.

\section{Diderot y la experiencia de Vincennes}

Como señalan los intérpretes de Diderot, éste no proviene de Ginebra como Rousseau ni de Burdeos como Montesquieu sino de la pequeña ciudad provinciana de Langres, que se había distinguido por una especial vinculación con los reyes de Francia. Lo mismo que sus paisanos el joven Diderot comienza aceptando una visión idealizada de la figura del rey. Especial predilección va a sentir por Enrique IV, como modelo del poder real, cuyas cartas al alcalde de su ciudad natal se guardaban celosamente en el ayuntamiento, y que Diderot va a copiar a su vez, formando parte después del llamado Fondo Vandeul.

Pero como en el caso de tantos jóvenes provenientes de provincias, la toma de contacto con la sociedad parisina también va a producir en Diderot una auténtica conmoción espiritual, con su consiguiente desarraigo. Durante un tiem- 
po, Diderot va a formar parte de una bohemia intelectual, en la que son frecuentes la miseria y la marginación. Es la dura pero a la vez instructiva escuela de la vida a la que también él se va a someter durante los primeros años de su estancia parisina. Cuando más tarde describa tan certeramente al sobrino de Rameau, podrá servirse para ello de su experiencia vivida. Según una interpretación plausible de $E l$ sobrino de Rameau, tanto "yo", que ejerce como la conciencia filosófica, como "él", que expresa la concepción subversiva del sobrino, vendrían a manifestar las dos almas que pugnaban entre sí en el interior del Diderot: el filósofo y el bohemio ${ }^{14}$. Este último tal como lo fue especialmente en la mencionada primera estancia parisina. Duro aprendizaje sin duda de las miserias de una sociedad que vegeta próxima a los brillos artificiales de la Corte. No resulta difícil imaginarse que ya empezaría a compartir aquello que hará decir más adelante al sobrino, cuando éste considera que su conducta cínica y parasitaria está en sintonía con los "hábitos de la sociedad", con las formas de vida de una sociedad corrupta. Tal situación no podía menos de afectar a la visión del Poder: "Ya no hay patria. De un polo a otro, sólo veo tiranos y esclavos" 15. De hecho, el joven Diderot, inmerso en la marginalidad parisiense, no sólo descubre los entresijos menos amables de aquella sociedad sino que empieza a verse confrontado con el binomio político-religioso, tan expresivo del universo ideológico del Antiguo Régimen. Diderot y su grupo son vigilados por la policía del rey y denunciados, dado el caso, por el cura de la parroquia. Todo ello contribuye a que tome una conciencia más clara del entramado ideológico del mundo en que vive.

Su interés por la política irá in crescendo a lo largo de su vida, en sintonía con la creciente politización del movimiento ilustrado. En un principio, tal como era habitual en la literatura clandestina, la obra de Diderot ataca primordialmente la religión tradicional como instancia última legitimadora del orden establecido. No obstante, ya en una obra de 1747, el Paseo del escéptico expresa con nitidez la bipolaridad de sus intereses estratégicos: "Imponedme silencio sobre la religión y el gobierno y ya no tendré más de que hablar" 16. A la bipolaridad del orden establecido va a responder la bipolarización del naciente pen-

14 H. R. Jauss, "Le Neveu de Rameau". Dialogique et dialectique (ou: Diderot lecteur de Socrate et Hegel lecteur de Diderot)", en Revue de Metaphysique et de Morale, Abril-Junio 1984, 14 ss.

15 O.C. V, 423.

16 O.C. I, 184. 
sador ilustrado. Pronto iba a tener la oportunidad de comprobar de forma más dramática el conflicto de los dos frentes en que se iba a escindir la dinámica ideológica del siglo.

En el verano de 1749 se produce una crisis y un estado de nerviosismo en las altas esferas del Poder. La opinión pública se atreve a responsabilizar al rey del descontento imperante. La corrupción, los escándalos y los rumores de bancarrota se encontrarían en su punto de partida. Ello motivó una redada no sólo contra los considerados desafectos al gobierno sino también contra los sospechosos en general. De esta acción cayó víctima también Diderot, detenido a finales de julio mediante una lettre de cachet real. Su destino fue la prisión de Vincennes, en las afueras de París. Ya en prisión, Diderot se entera de que se le ha encarcelado por sus escritos, especialmente por la Carta sobre los ciegos, e incluso por alguna obra que se le atribuía indebidamente. Era comprensible que tanto él como sus correligionarios evocaran inmediatamente la figura de Sócrates como símbolo de la virtud perseguida. Sócrates fue, en efecto, uno de los grandes referentes que Diderot tomó a lo largo de su vida. No obstante advierte prontamente que no basta estar injustamente en la cárcel para adoptar sin más un comportamiento digno de Sócrates. El filósofo comprometido que siempre fue Diderot, tomó tempranamente conciencia de que no tenía vocación de mártir. "No hay ninguna clase de martirio del que ambicione el laurel" escribirá más adelante en La paradoja del comediante 17.

Pero la experiencia de la prisión, de la que saldrá a comienzos de noviembre, también le va a servir para tomar conciencia de la naturaleza del Poder. En un momento en que ya estaba comprometido con el proyecto enciclopédico, Diderot tiene la oportunidad de meditar acerca de las prudencias y estrategias a utilizar frente a un Poder que se le mostraba hostil. La visión mitificada de la realeza tocaba a su término. En adelante se le impondrán dos tareas: la de jugar astutamente con el Poder y a la vez la de intentar, en sintonía con el espíritu de la Ilustración, acercar a los que detentan el Poder a las nuevas ideas, la de intentar racionalizar el Poder para ser capaces así de llevar a buen término el proyecto ilustrado. 


\section{El proyecto enciclopédico y el problema del Poder}

Al ser encarcelado, Diderot se humilla o finge humillarse ante los representantes del Poder, con vistas a lograr su próxima liberación. Cuando finalmente ésta se produce, al cabo de tres meses, ello ocurre bajo la promesa de no hacer nada en el futuro que fuera contrario a las "buenas costumbres" y a la "religión". Pero Diderot no estaba solo. En seguida suscitó la solidaridad del ascendente movimiento ilustrado, como es el caso de Voltaire o el del entonces amigo, Rousseau. Pero si la Ilustración comenzaba a ser ella misma una nueva forma de Poder ideológico, por su ascendiente sobre la opinión pública, también lo comenzaba a ser desde la perspectiva económica, debido a un grandioso proyecto, entonces en ciernes. Nos referimos, claro está, al proyecto enciclopédico, a cuyo frente se hallaba precisamente Diderot. No es extraño por tanto que el mismo día en que se produjo su detención, los editores recurrieron a los representantes del gobierno solicitando la liberación del prisionero, alegando que, de lo contrario, la empresa de la Enciclopedia se vendría abajo, al ser Diderot la única persona "capaz de llevar adelante un proyecto tan vasto y que poseería, por sí solo, la clave de todo el conocimiento" 18 . De este modo, el proyecto enciclopédico se iniciaba en el marco de una compleja relación con el Poder, de forma que no siempre coincidian los intereses ideológicos y los económicos en lo relativo a una empresa que iba a dar trabajo a miles de trabajadores a lo largo de veinte años, aparte de notables ganancias a los editores. De ahí toda una serie de ambigüedades y sobreentendidos que presidieron las relaciones de los enciclopedistas con el poder.

Al salir de la prisión, Diderot había prometido silencio al Poder pero la opinión pública y los suscriptores de la Enciclopedia le presionaban precisamente en sentido contrario. Diderot va a tener que desplegar toda su habilidad para hacer frente a la complejidad de la situación. La Enciclopedia no era un opúsculo más que se pudiera imprimir impunemente de una forma clandestina, tal como va a ser frecuentemente el caso a lo largo del Siglo de las Luces. Se trataba por el contrario, como se indica con complacencia al comienzo del volumen VIII, de "la obra más amplia que quizá se haya concebido" nunca. Ello obligaba a inevitables componendas con el Poder, en un principio hostil, aunque no desprovisto de conflictos y contradicciones. Era preciso idear una estrategia pa-

P. N. Furbank, Diderot, Barcelona, 1994, 68 ss. 
ra ir comunicando, al menos insinuando, aquella Verdad que se consideraba patrimonio irrenunciable del movimiento filosófico. No sólo estaba presente la amenaza de la censura sino que los enciclopedistas practicaron ampliamente la autocensura, en evitación de mayores males. Condorcet en el Bosquejo señala que los ilustrados a menudo cubrían la verdad con un velo, "dejando el placer de adivinarla". Ello fue cierto sobre todo en el caso de los enciclopedistas. Ya la misma dedicatoria de la Enciclopedia al ministro d'Argenson constituye de por sí un símbolo de los compromisos con el Poder. Sin caer en el servilismo, d'Alembert va a considerar al cortesano como el papel más bajo que pueda desempeñar un hombre de letras ${ }^{19}$. Por el contrario, los directores de la Enciclopedia, a la vez que dejan barruntar que tal dedicatoria es producto de las circunstancias, no ocultan la autoconciencia de la intelligentsia ilustrada frente al Poder. Si éste pretende ir más allá de la sumisión ciega y sospecha de los cortesanos y se preocupa por su imagen ante otro tipo de instancias como son la opinión pública, los extranjeros y, por último la posteridad, entonces es preciso recurrir al juicio de los que piensan, a saber, a las Gentes de letras y sobre todo a la "nación libre y desinteresada de los filósofos" 20 . Por poco viable que parezca, D'Alembert y Diderot no pueden menos de sugerir la necesidad de colaboración de la Filosofía y el Poder. Se trata, claro está, de un desideratum acerca del que no cabía hacerse muchas ilusiones.

De ahí el ponderado cálculo de lo que se podía decir. Los artículos relativos a la religión y a la política estaban condenados a ser más convencionales, por ser el objeto de un exámen más minucioso por parte de la censura, mientras que, por el contrario, otros, en principio inocuos, contenían con frecuencia una carga en profundidad. Se expresaban a menudo quejas de que no se pudiera decir la verdad de forma clara. Sin embargo pronto quedó fuera de duda que el convencionalismo de muchos artículos era compensado con creces por la impresión producida por ese balance e interpretación globales del saber moderno, que convierten a la Enciclopedia en una de las maravillas del hombre mundo, en expresión de U. Eco ${ }^{21}$. Correlato ilustrado de las Sumas medievales, la Enciclopedia se presentaba como la epopeya del hombre moderno, como balance autocomplaciente de lo que este había aportado en el campo de las ciencias, de

19 D'AlEMBERT, Melanges de litterature, d'bistoire et de philosophie, I, Amsterdam, 1767, 372.

20 Encyclopédie, I, Dedicatoria.

21 Cfr. Conversación con Diderot, en P. N. Furbank, op. cit., 11. 
las artes y también de los oficios. Pero desde los estudios de Fr. Venturi los intérpretes más lúcidos de la obra de Diderot observan como la finalidad última de la Enciclopedia es "política" en un sentido amplio, a saber, aspira a la configuración de un ciudadano más crítico, más racional, más tolerante y comprometido con la causa de la humanidad. Así ocurre, por ejemplo, en el artículo "Enciclopedia", que constituye uno de los manifiestos principales de toda la obra. Ya al comienzo mismo, observa Diderot que la finalidad de una Enciclopedia, al reunir los conocimientos dispersos sobre la faz de la tierra, consiste en lograr no sólo su comunicación a la humanidad actual sino en poner las bases para que las generaciones futuras, al hacerse más instruidas, se hagan también más "virtuosas" y más "felices" 22. Recordemos que la llamada "política de la felicidad" constituía uno de los tópicos más socorridos del pensamiento político ilustrado. Diderot está convencido de que una obra de la envergadura de la Enciclopedia, y teniendo en cuenta además las circunstancias en que tuvo que ser elaborada, tiene que tener necesariamente muchos defectos, pero todo ello puede resultar bastante irrelevante si cumple su cometido fundamental: cambiar la forma común de pensar, en definitiva si contribuye a la formación de un nuevo tipo de ciudadano. En realidad se ha podido escribir que a menudo lo más propiamente político de la Enciclopedia se encuentra en los artículos no abiertamente políticos, en los que Diderot puede dejar traslucir más claramente su concepción de un nuevo modelo social y político. Así ocurre, por ejemplo, con el famoso artículo "arte" dedicado a la exaltación de las artes mecánicas y que constituye sin duda otro de los más señalados manifiestos de la obra. El baconismo de Diderot encuentra aquí su nítida expresión y con ello la decidida voluntad de superar la infravaloración del trabajo material de que adolecía la sociedad tradicional. Al hacerlo así, Diderot se convierte a su manera en portavoz de los nuevos valores burgueses, en la proximidad de la revolución industrial y de la conquista por el poder político por una nueva clase social. Si Voltaire, a raíz de su estancia en Inglaterra, había acentuado la crítica de los valores obsoletos del Antiguo Régimen, en contraposición con las nuevas formas sociales y económicas que emergían más allá del Canal, también ahora Diderot, a pesar de la complejidad de su pensamiento, tiene entre sus señas de identidad la defensa de la razón instrumental: "Lo útil lo circunscribe todo" 23. Por ello tratándose de las artes mecánicas es preciso poner los principios de su funciona-

22 Encyclopédie, V, art. "Encyclopédie”, 635.

23 O.C. II, 13. 
miento a disposición de todos, más allá de las estrecheces gremiales, para el bienestar futuro de la humanidad.

Junto con ello comenzaban a aparecer artículos de contenido abiertamente político como el de "Autoridad política", en los que, a pesar de todas las cautelas e inhibiciones, estaba claro que Diderot se situaba en unas coordenadas ajenas a las que legitimaban al Antiguo Régimen. Diderot se sitúa en la línea del moderno iusnaturalismo, después de su lectura de autores como Locke y Pufendorf. A pesar de sus reticencias, quedaba claro que su horizonte no era ya el de Bossuet y el de la monarquía absoluta.

Teniendo todo ello en cuenta, es comprensible que la polémica antiilustrada arreciara a partir del inicio de la publicación de la Enciclopedia en 1751, viendo en una obra de dicha envergadura, con su intento de interpretación global de la cultura moderna, un peligro mayor contra el orden establecido que el que podía provenir de un escrito aislado de un pensador ilustrado. A pesar de sus convencionalismos e inhibiciones, la Enciclopedia era considerada como una especie de "machine de guerre" contra la que había que rebelarse. De ahí la temprana movilización de los órganos de opinión afines al Antiguo Régimen, comenzando por el Journal de Trévoux. Haciéndolo así dejaban bien al descubierto su inercia intelectual, su incapacidad para seguir críticamente las nuevas ideas. La acusación fundamental consistía en afirmar que dichas ideas minaban los fundamentos de la religión y del Estado. En este intento de rechazo y descalificación globales, Diderot, el director de la Enciclopedia, era quien salía peor parado. Así lo constata este texto de Grimm, de 1752: «El senor Diderot, es entre los autores de la Enciclopedia, aquél a quien más se acusa de trabajar contra la religión, la autoridad real y las costumbres" 24 . De ahí que el "filósofo" se viera, de buen o mal grado, cada vez más inmerso en el debate político.

En el entorno del rey no faltaban personajes lúcidos que opinaban que el soberano, habiendo salido debilitado de sus confrontaciones con los sectores más poderosos del Estado, tendría la oportunidad de recuperarse poniéndose al frente del movimiento ilustrado, detentador de un nuevo tipo de autoridad intelectual y moral. Así opinaba en concreto el marqués d'Argenson quien no dudaba en escribir en su diario: "Si Enrique III fue obligado a ponerse a la cabeza de la Liga, Luis XV debería ponerse al frente de la filosoffa, de la justicia y

24 Correspondance litteraire, VII, 122. 
de la razón para consolidar su poder y su felicidad" 25 . Tal no fue ciertamente el caso. Como observa en otro lugar el mencionado autor: "el gobierno, amedrentado por los devotos, se ha vuelto más censor, más inquisidor, más miserable en materias filosóficas" 26 . De hecho, aparecidos los dos primeros volúmenes de la Enciclopedia, se procede en 1752, en un clima enrarecido, a su supresión, en cuanto emblema de las nuevas ideas. El texto de la supresión no deja lugar a equívocos acerca del horizonte ideológico del Antiguo Régimen, al señalar que en la Enciclopedia "se habían querido insertar diversas máximas tendentes a destruir la autoridad real, a establecer el espíritu de independencia y de rebelión y, en términos oscuros y equívocos, a ensalzar los fundamentos del error, de la corrupción de las costumbres, de la irreligión y de incredulidad" 27. Toda la inercia ideológica del antiguo Régimen aparece reflejada en este texto.

La publicación, no obstante, va a poder ser retomada, a pesar de la precariedad de la situación y de la sutileza de los equilibrios que es preciso emplear. Pero una segunda grave crisis va a sobrevenir en 1759 a raíz de la publicación de Del espiritu de Helvetius. D'Alembert, cansado y escéptico, abandona su puesto de codirector, pero Diderot va a continuar hasta el final, ofreciéndonos así un caso claro de militancia y de compromiso con las nuevas ideas. No es extraño que en este difícil forcejeo se planteara a menudo la idea de proseguir en algún lugar del extranjero la publicación de la obra. Invitaciones para ello no faltaron. Por otra parte no dejó de ser utilizada tal posibilidad como arma de presión contra el Poder. Aparte del apoyo de un sector cualificado de la opinión pública francesa, los enciclopedistas podían jugar la carta de los perjuicios económicos que un eventual traslado al extranjero podría ocasionar, junto con el deterioro de la imagen internacional de Francia que se mostraría incapaz de acoger en su seno un monumento a la cultura moderna como era la Enciclopedia. La oferta más significativa provino de Catalina II que en 1762 ofrece claramente esa posibilidad a Voltaire, otro abanderado de esa solución. Voltaire, a su vez, se la transmite a Diderot. Este le escribe una famosa carta el 29 de septiembre de 1762, rechazando tal sugerencia. No sólo habría dificultades de orden legal: el manuscrito de la Enciclopedia está en manos de los editores que han pagado por ello, sino que el desarrollo del proyecto en su país provoca en el ánimo de Diderot una de sus más nítidas profesiones de fe ilustrada. No creáis, le

25 Cfr. R. ReICHARDT y E. SCHMITT, op. cit., 21.

26 Ibid. 22.

27 F. VENTUR, Los origenes de la Enciclopedia, Barcelona, 1980, 166-167. 
escribe a Voltaire, que el trabajar en medio de bárbaros "me vuelve pusilánime". Por el contrario, se reafirma en el objetivo del combate ilustrado: luchar sin desfallecer contra los supersticiosos, los fanáticos, los ignorantes, los locos, los malos, los tiranos. El Diderot que no se sentía particularmente llamado al heroísmo o al martirio no duda, sin embargo, en preguntarse: ¿es que acaso la mentira ha de tener sus mártires y la verdad sólo ha de ser defendida por cobardes? No se puede ser filósofo "en vano" 28. La lucha ilustrada se le presenta como una lucha no sólo teórica sino también moral. No sólo es preciso mostrar que saben más que sus adversarios sino también que son mejores porque luchan por la emancipación de la humanidad y no por su opresión.

Es el lenguaje de un Diderot comprometido con la Ilustración, a pesar de todos los obstáculos. Años más tarde, en sus conversaciones con Catalina II, no omitirá referirse al combate enciclopédico, por aquel entonces llevado a buen término: "He trabajado cerca de treinta ańos en esta obra: de todas las persecuciones que cabe imaginar no hay ninguna que no haya tenido que soportar" 29. Ello le habría supuesto haber arriesgado su honor, su fortuna, su libertad. Fue preciso luchar nada menos que con la oposición de la Corte, los Grandes, los militares, el clero, la policía, los magistrados... En términos análogos se había pronunciado ya con anterioridad, en el importante Avertissement del volumen VIII, en el que se refiere a la infinidad de obstáculos "morales" con que tropezó el proyecto enciclopédico y para los que no estaban preparados. Aparte de las dificultades intrínsecas que podía presentar un proyecto así, habría sido preciso luchar contra la "envidia", la "mentira", la "ignorancia", el "fanatismo". Diderot alude una vez más a la dimensión moral del combate ilustrado para explicar la potencialidad de esa lucha: "El hombre de bien es capaz de un entusiasmo que el malvado desconoce".

En medio de esta carrera de obstáculos, la colaboración con el Poder continúa siendo, a pesar de todo, un desideratum insoslayable, pues no sólo la viabilidad del proyecto ilustrado depende de ello sino también el asentamiento del propio Poder sobre bases más firmes. Así lo expresa Diderot en el mencionado Avertissement: "Compete a los amos del mundo apresurar esta feliz revolución. Son ellos quienes ensanchan o estrechan la esfera de las Luces. ¡Felices los tiempos en que todos ellos habrán comprendido que su seguridad consiste en go-

28 O.C. XIX, 464.

29 D. Diderot, Mémoires pour Catherine II, ed. P. Vernière, París, 1966, 262. 
bernar sobre hombres instruidos!" 30 . La Filosofía y el Poder habrían de hacer converger sus esfuerzos.

Es preciso establecer una comunicación entre el Poder y la voluntad de la nación a través de una especie de infraestructura que recorre el Siglo de las Luces: la opinión pública. Ello implica la libertad de imprimir tanto libros como periódicos, con vistas a articular dicha opinión, tal como indica el propio $\mathrm{Di}$ derot en un escrito coetáneo a la Enciclopedia, su importante Memoria sobre la libertad de imprenta (1763). Si el gobernante no actúa sobre una opinión ilustrada y autoconsciente, ¿qué diferencia habría entre él y "un pastor que conduce su ganado?”. Precisamente todo el proyecto enciclopédico está dominado por una profunda voluntad pedagógica que trata de incidir críticamente en la configuración de esa opinión pública. Esta última, mediante sus diputados debidamente seleccionados, ha de informar al Poder acerca de la verdadera naturaleza de sus necesidades.

Pero si el proyecto político de Diderot puede resultar impreciso y genérico, dentro de su voluntad indiscutible de modernización - sólo con Turgot los proyectos políticos ilustrados alcanzarán un nivel satisfactorio de precisión-, cabría aludir aquí, a modo de microcosmos político que sintetiza teoría y praxis, a la creación de un "partido enciclopédico" que estaría compuesto tanto por los colaboradores de la obra como por los suscriptores. Es mérito de J. Proust haber llamado la atención sobre este punto ${ }^{31}$. Tal "partido" habría tenido como finalidad, en primer lugar, la articulación de la opinión pública, a que hemos hecho alusión. Basta leer el Avertissement del tercer volumen, después de la suspensión de 1752, para caer en la cuenta de la importancia que los editores concedían a este punto. Pero también va a servir como eficaz plataforma para copar puestos en las Academias y para colocar a alguno de los suyos en la esfera del Poder político. Por supuesto no llegó a suponer ninguna alternativa real al Poder establecido pero constituyó algo así como una república ideal, como un referente utópico en el que poder mirarse, pues tenía la gran ventaja de que no se trataba de una construcción más o menos fantasiosa, sino que se presentaba en su concreción empírica, en el seno de la sociedad de su tiempo.

30 Encyclopédie, VIII, Avertissement, 2.

31 J. Proust, "Diderot o la política experimental", en Revista de Estudios Politicos 41 (1984), 10. 


\section{Diderot y Catalina II}

Tratando de aproximarnos a aquel período de la vida y la obra de Diderot en que de una forma más inmediata ha tratado de ejercer como "preceptor de príncipes", una vez concluida la ingente labor de la Enciclopedia, quizá convenga comenzar haciendo alguna alusión a un significativo escrito de los años sesenta, publicado como prólogo a las Investigaciones sobre el origen del despotismo oriental de N. A. Boulanger, y que es atribuido a Diderot. Ha sido editado con el título de La Europa racional y constituye sin duda una de los manifiestos más agresivos de la Ilustración ${ }^{32}$. Durante la década de los sesenta a los setenta Diderot está en estrecho contacto con el salón d'Holbach, a cuyas discusiones debe un influjo importante en su ulterior formación política. Rememorando la doble temática aludida tempranamente en El paseo del escéptico, también ahora, al informar de los contenidos de sus conversaciones en el salón holbachiano, nos va a decir que versaban bien sobre la política bien sobre la religión. Es decir, el núcleo de la confrontación entre los ilustrados y sus adversarios ideológicos, pero planteado ahora el problema en un momento en que el bando ilustrado había ganado muchas posiciones. Un optimismo especial tenía que infundir a los ilustrados el haberse recuperado de la gran crisis de finales de los años cincuenta, que había conducido a la segunda suspensión de la Enciclopedia.

No es extrańo que en estas circunstancias vuelva a plantearse el problema de la sustitución del viejo triángulo ideológico que articulaba el universo del Antiguo Régimen: el Sacerdote, el Príncipe y la Voluntad divina por el del Filosofo, el Príncipe y la Voluntad general.

El texto de La Europa racional contrapone radicalmente ambos modelos y da expresión de una forma paradigmática a la peculiar utopía ilustrada de una alianza entre la Filosofia y el Poder. Escrito en un espíritu profundamente antirreligioso, muy en la línea de d'Holbach, este pequeño ensayo describe la situación de caos y anarquía ideológicos a que habrían ido a desembocar las ideas religiosas, arrastrando consigo también a las organizaciones políticas que habían ido vinculando su destino a la tradición religiosa. Ante esta situación de anarquía, sólo la Filosofía y la Razón podrían indicar una salida: "La Filosofía y la Razón son las únicas que pueden hoy reconducir la civilización hacia sus

32 “La Europa racional”, en Debats, n. 9 (1984), 82 ss. 
antiguos principios y rescatarla de la esclavitud en que se encuentra" 33. Ante la crisis de los antiguos valores, la Filosofía estaría investida de una misión histórica. Tratando de iluminar el futuro de la humanidad, la Filosofía habría de elaborar un "proyecto de filosoffa política" que oriente al Poder en su nueva andadura, convirtiéndose en una "ciencia del Estado" con vistas a preparar el advenimiento de una nueva Europa, la "Europa racional", ese proyecto genérico hacia el que de una forma más o menos imprecisa se encaminaban los ilustrados. En un momento de consolidación del movimiento ilustrado, el autor comparte la ilusión de un maridaje entre Filosofia y Poder, como fruto no tanto de un feliz azar cuanto debido a las consecuencias que cabe esperar del "progreso del conocimiento" en que estaba sumida la humanidad.

Pero ya conocemos las limitaciones de la situación francesa y la apertura de sus ilustrados a la opinión pública internacional, dentro del horizonte de la llamada Europa francesa. Una forma especial de esta relación la constituyó la mantenida con un serie de soberanos europeos, de una forma u otra interesados en el nuevo movimiento de ideas. Un importante vehículo de comunicación lo constituyó la Correspondencia literaria de Grimm, a la que estaban abonados una quincena de mandatarios, entre ellos Catalina II. Los ejemplares de los príncipes circulaban también entre sus familiares y cortesanos. De esta forma se establecía una interrelación especial entre la Ilustración y el Poder. Pues bien, Diderot fue un destacado colaborador de la Correspondencia, iniciando así una segunda experiencia política, después de la vivida como director de la Enciclopedia. Diderot va a publicar ahora los Salones y gran parte de los Cuentos en este órgano selectivo. Aunque fuera de forma indirecta, de todas estas publicaciones de Diderot se deducía una nueva visión de la autoridad, distinta de la tradicional, como cabría observar de una forma especial en el relato de Jacques el fatalista, en las relaciones que mantiene el amo con su criado y la anfitriona ${ }^{34}$.

Pero quedaba un último paso en este proceso de acercamiento a los detentadores del Poder. Este paso se va a dar mediante el conocido viaje a Rusia, a la Corte de Catalina II, constituyendo la experiencia rusa de Diderot un capítulo significativo en la historia de la confrontación del intelectual con el Poder. Ya sabemos que Diderot aceptaba gustoso el calificativo de "filósofo" con el que le

33 Ibid., 86.

34 J. PROUST, Diderot o la politica experimentah 11-12. 
honraban a menudo sus coetáneos. Por su parte Catalina II constituía una clara personificación de la Prepotencia del Poder, al que trataba de aunar con la apertura a los principios de la Ilustración. De hecho Catalina, desde su ascenso al trono en 1762 había constituido una referencia constante en la vida de Diderot. Le había ofrecido la posibilidad de proseguir la publicación de la Enciclopedia en su Imperio. Más tarde, para solventar dificultades económicas del filósofo, le compra su biblioteca, si bien le nombra su director vitalicio. Su situación económica, siempre precaria, cambia entonces notablemente. Ejerce además de consejero cultural de Catalina para quien recluta artistas que van a trabajar a su Corte, como es el caso de Falconet. Se fue labrando así una relación especial entre uno de los representantes más significados del despotismo ilustrado y el director de la Enciclopedia, que tantas dificultades habla encontrado en su propio país para llevar a buen término el gran diccionario. Un Diderot que por otra parte tampoco se va a mostrar tan entusiasta del modelo inglés como otros conspicuos representantes del Siglo de las Luces como Voltaire y Montesquieu. La máxima Salus populi suprema lex esto se habría quedado reducida allí a una mera expresión sobre el papel ${ }^{35}$. Bien es verdad que había otro gran representante del despotismo ilustrado que aspiraba como ninguno al título de rey-filósofo. Se trata, obviamente, de Federico II que mantuvo estrechas relaciones con varios representantes de la ilustración francesa. Diderot en un principio se mostraba prudente al respecto, pero cuando Federico somete a una dura crítica el Ensayo sobre los prejuicios de d'Holbach, Diderot cree descubrir la verdadera naturaleza del despotismo de Federico, condición que va a denunciar abiertamente varias veces a lo largo de su obra. Federico se le presenta como un príncipe ambicioso, sin escrúpulos, un príncipe dispuesto a sacrificarlo todo, incluso la felicidad de sus súbditos, a sus ansias de poder...Un mito menos en los espejismos de Diderot. Por ello en su sonado viaje a Rusia, tanto a la ida como a la vuelta, evita pasar por la Corte de Federico, para irritación de éste.

Quedaba la opción rusa que con Catalina al frente también había llegado a interesar al movimiento ilustrado. A. Lortholary escribió a comienzos de los años cincuenta un libro significativo sobre el tema: El espejismo ruso en la Francia del siglo XVIII ${ }^{36}$. Pero su abanderado va a ser sobre todo Diderot que había

35 Véase el importante estudio introductorio de P. VERnière a su edición de las Oeuvres Politiques de Diderot, París, 1963, XXIV-XXV.

36 A. LORTHOLARY, Les philosofes du dix-huitieme siécle et la Russie: le mirage russe en France au dix-huitiéme siécle, París, 1951. 
sido objeto de tantas deferencias por parte de la emperatriz, a las que correspondía el filósofo con sus manifestaciones de reconocimiento. Era tentador para una persona como Diderot considerar que las deferencias imperiales constituían un testimonio de la ascendencia de los principios filosóficos en un representante cualificado del Poder. Lo que no sospechaba era el gran carácter publicitario que las manifestaciones públicas de reconocimiento y sobre todo su viaje hasta la lejana Rusia iban a tener para Catalina en la proyección de su imagen internacional. Por el contrario, la imagen de Diderot va a quedar lastrada durante mucho tiempo por su actitud ante la emperatriz. Llegó a formarse la idea de un Diderot cortesano, adulador del Poder, ante el que se había mostrado servil. Robespierre y Sacher-Masoch habían fomentado esta leyenda. De una forma especialmente cáustica se expresaba P. Sylvain Marechal, a comienzos del siglo XIX, cuando afirmaba que Catalina había atraído a Diderot junto con otros hombres de letras, a su peculiar "jaula de fieras", de los que dispondría a su antojo como de animales domésticos. En realidad durante un tiempo se conocieron mucho mejor los elogios de Diderot que sus apreciaciones críticas a la política de la emperatriz. Algunos textos sólo fueron publicados y conocidos mucho más tarde. Así, las llamadas Memorias para Catalina II lo fueron en 1899. Hoy nuestra imagen del filósofo, por más que sigan persistiendo dudas y ambigüedades, es mucho más diferenciada y ajustada a la realidad. Estudios como los de P. Verniére, J. Proust, G. Dulac han contribuido poderosamente a una mejor comprensión de este delicado capítulo de la vida del filósofo, en el que de un modo neurálgico se planteaban las relaciones entre la Filosofía y el Poder.

Pero vayamos por partes. Después de haber tenido una relación prolongada con Catalina, Diderot emprende su famoso viaje a Rusia, donde va a permanecer desde octubre de 1773 hasta marzo de 1774 . La meta del penoso viaje era algo más que agradecer personalmente a la emperatriz los favores recibidos. Diderot aspiraba a acercar lo más posible a un destacado representante del Poder a los principios de la Ilustración. Se trataba para él de una experiencia única que le deparaba la oportunidad de enfrentarse directamente con la emperatriz, teniendo la posibilidad de departir ampliamente con ella a lo largo de su estancia en la Corte. Tarea ciertamente no fácil por muchos motivos. Si a lo largo de la elaboración de la Enciclopedia tuvo que echar mano de toda su habilidad en el juego con el Poder, para llevar a cabo la empresa comenzada, esa habilidad no le va a ser ahora menos necesaria. Situado frente a frente ante una representante cualificada del Poder, a la que debía varios favores, Diderot se va a esfor- 
zar por conciliar la expresión de su agradecimiento y la fidelidad básica a sus principios filosóficos y morales, sobre los que tanto había insistido. Por otra parte estaba la tensión entre la visión del mundo propia del "filósofo" y la de quien tenía la responsabilidad del "gobierno" de su inmenso país. No sólo se trataba de la tópica confrontación teoría-praxis sino de la confrontación del filósofo con un mundo que en gran medida le resultaba extraño. No deja de impresionar el idealismo de un Diderot viajando solo hasta la lejana Rusia para este prolongado encuentro con la emperatriz. La presencia inmediata de ésta le resultaba estimulante por la personalidad de Catalina y, además, tenía la esperanza de que Rusia, un Imperio nuevo, se podría mostrar más permeable a las nuevas ideas que un país obsoleto, con viejas ataduras, como era el caso de su Francia natal ${ }^{37}$.

Leyendo las Memorias para Catalina II, que contienen los textos que servían de base para sus conversaciones con la emperatriz, y las Observaciones sobre la Instrucción de la emperatriz rusa, escritas a su retorno de Rusia, la impresión global que cabría sacar es sin duda la de un innegable candor, pero también la de una indiscutible sabiduría por parte de alguien que no sólo trataba de conocer la situación rusa lo mejor posible sino que en cuanto filósofo hace toda una serie de observaciones pertinentes acerca del buen gobierno del Estado. Es cierto que el estilo adoptado resulta a menudo acomodaticio y ditirámbico: Catalina reúne en su persona "el alma de una romana y los encantos de Cleopatra" y otras expresiones por el estilo. Pero aparte del innegable impacto que le producía la presencia inmediata de la emperatriz, también cabría ver en ello una especie de estratagema para atraer a Catalina a su campo, como pidiéndole "disculpas" por su osadía de ejercer como "preceptor de príncipes". Diderot es consciente de que sus conversaciones con Catalina vienen a constituir una apasionante escenificación teatral en la que, evocando el diálogo de El sobrino de Rameau, cabría afirmar que ahora sería propiamente Diderot quien hace de alguna forma de "sobrino" ante la emperatriz ${ }^{38}$. Lo que interesa en todo caso a los ojos de Diderot es ser "útil" a la causa ilustrada y al buen gobierno de Rusia. Por ello tampoco le importa calificar sus reflexiones como "ensoñaciones", siempre que consigan la meta propuesta. Seguramente sea cierta la afirmación según la que para Diderot se trataba de una obra de teatro pero con un fin se-

37 Véase el estudio introductorio de P. VERNIERE a su edición de las Mémoires pour Catherine $I I, 3$ ss.

38 R. LEWINTER, Diderot ou le mots de l'absence. París, 1976, 183. 
rio, mientras que para Catalina se trataba más bien de una obra de teatro a secas, por más paciencia que haya mostrado en escuchar a su interlocutor y por más que parezca haber mostrado hacia él una apertura mayor de la que Federico habia mostrado hacia Voltaire.

Ateniéndonos a la intervención de Diderot, cabría decir que por muy complaciente que se haya mostrado con la emperatriz, se atreve a decirle que todo gobierno arbitrario es malo incluso si se trata de un "amo bueno, firme, justo e ilustrado". Dicho tipo de gobierno habitúa a los pueblos a respetar a un amo, sea cual fuere, privándoles de un derecho "natural, inalienable y sagrado" como es el derecho a deliberar, a oponerse. Por ello incluso siendo el mejor de los hombres, el déspota que gobernara conforme a su capricho, "comete delito", pues en definitiva reduce a sus súbditos a la condición de animales 39 .

De ahí, además, la evidencia para Diderot, de la fragilidad del ejercicio del poder personal de Catalina en un inmenso país desprovisto de la debida articulación política, que llenara el vacio existente entre la emperatriz y el pueblo. Según ha observado G. Dulac, en sus conversaciones con Catalina, Diderot trata por todos los medios de convencerla de que el futuro de un pueblo como el ruso no podía basarse en la voluntad solitaria y efímera de un soberano, sino que habría de ser más bien el resultado del esfuerzo colectivo que diera solidez y estabilidad a la vida política ${ }^{40}$. De esta forma se podría obviar a la vez el voluntarismo reformista que trata de modernizar al pueblo mediante la acción de una minoría cualificada pero carente de verdadera inserción en la sociedad. Por ello, por más que acepte la voluntad reformadora y modernizadora de Catalina, considera, no obstante, que está mál enfocada: "Comenzáis la obra por el tejado". El antiguo enciclopedista que tanto había insistido en el fomento de la educación y en el cultivo de las artes mecánicas, le recuerda a Catalina sus viejas convicciones: "En todo hay que comenzar por el principio, y el principio es poner en marcha las artes mecánicas y las condiciones de base" 41 . Sólo sobre este fundamento encontrarán su asiento las minorías cualificadas, sólo así se podrían poner los cimientos para subsanar una de las grandes lagunas del país, la ausencia de una clase media.

39 Escritos politicos, ed. cit., 127.

40 G. Durac, "El filósofo y el autócrata: algunos aspectos de un trabajo político", en Revista de Estudios Politicos 41 (1984), 56-57.

41 D. Diderot, Melanges et morceaux diverses. Contributions á l'Histoire des deux Indes, II, ed. a cargo de G. GoGGı, Siene, 1977, 356. 
Catalina no dejó de admirar varios aspectos de la personalidad de Diderot. No dudaba en considerarlo como uno de los hombres más extraordinarios que hayan existido, pero ello no implicaba que estuviese dispuesta a convertirse en discípula suya, al menos en el ámbito político. Por más que el filósofo y la emperatriz podían coíncidir en el diagnóstico de muchos males que aquejaban al Imperio ruso, sus enfoques se iban a mostrar discrepantes. Después de algunos intentos en sentido contrario, Catalina se había convencido de que en Rusia sólo podía tener éxito la vía autocrática, siguiendo las huellas de Pedro el Grande. Diderot es consciente de tal situación y aun cuando persiste en su aprecio y afecto hacia Catalina, percibe con mayor nitidez la verdadera índole del llamado despotismo ilustrado y, en definitiva, el carácter mostrenco de lo político. A su retorno de Rusia escribe sus Observaciones sobre la Instrucción de la emperatriz de Rusia, la Instruccion redactada por Catalina en 1768 con vistas a una supuesta reforma legislativa que se iba a llevar a cabo en el Imperio ruso. Conocido tal proyecto en Europa sirvió eficazmente a la propaganda de la emperatriz, pero en la propia Rusia tal proyecto nunca llegó a ser desarrollado y puesto en práctica. Diderot escribe un comentario crítico sobre tal documento, que Catalina conocerá con indignación más tarde, una vez muerto ya Diderot. A la emperatriz le habría bastado con leer el simple comienzo del texto de su interlocutor para montar en cólera. Dice así: "No hay más soberano verdadero que la nación; no puede haber más legislador verdadero que el pueblo" ${ }^{42}$. Ciertamente a lo largo del texto los elogios y el estilo laudatorio alternan con apreciaciones críticas. En cualquier caso la "conclusión" conecta claramente con el talante del comienzo. Refiriéndose a la impresión global que le produce dicha Instrucción, Diderot escribe de una forma taxativa: "Veo que allí se renuncia al nombre de déspota, pero la cosa se conserva, al despotismo se le llama monarquía.

"No veo que se proyecte ninguna disposición para la liberación del cuerpo de la nación; y sin embargo, sin liberación o sin libertad, ninguna propiedad; sin propiedad, ninguna agricultura; sin agricultura, ninguna fuerza, ninguna grandeza, ninguna riqueza, ninguna prosperidad" 43 . Lo contrario de la meta hacia la que apuntaba el "magisterio" del filósofo ante la emperatriz. Frente a los elogios hiperbólicos con que obsequió a Catalina, las manifestaciones críticas nos ayudan a recomponer la imagen de Diderot, aunque ello resultara mucho más difícil para sus contemporáneos. Parece afirmarse que, dejando a un

42 Escritos políticos, 183.
43 Ibid., 300. 
lado flaquezas e incongruencias coyunturales, y asimismo el complejo problema de su peculiar estilo cuando se dirige a la emperatriz, Diderot supo cumplir con dignidad su difícil cometido de hablarle a la cara al Poder. Pero los resultados no dejaban de implicar una decepción, no dejaban de suponer la constatación de la impotencia para influir en una transformación efectiva del Poder. Como contrapunto, su visión política se vuelve más crítica. Ve con mayor nitidez la verdadera naturaleza del despotismo ilustrado y su incapacidad para asumir de una forma coherente y profunda los principios ilustrados.

En esta especie de repliegue espiritual, de retorno del filósofo a sí mismo, Diderot recuerda el carácter universal del magisterio filosófico. El filossofo ha de dirigirse por supuesto al soberano para intentar reconciliar la acción política con las exigencias de la razón, pero también ha de dirigirse a los pueblos, a los que hay que redimir de su ignorancia, tal como queda apuntado ya. La colaboración en la obra de Raynal, la Historia de las dos Indias, le va a ofrecer la posibilidad de reorientar su magisterio filosófico en torno a las relaciones entre Filosofia y Poder. Obra monumental, que algunos no dudan en comparar con la Enciclopedia, se fue enriqueciendo a lo largo de sus tres primeras ediciones 1772,1774 y 1781 . No se trata de una historia cualquiera sino de una historia "filosófica y política" muy en el estilo de la llustración, que también era compartido por Diderot. Estudiosos como M. Duchet, Y. Benot y G. Goggi, entre otros, han puesto de manifiesto la relevancia de las reflexiones políticas de esta última etapa de Diderot, sobre la que apenas se había reflexionado anteriormente. Decepcionado respecto a las posibilidades de racionalización política de que se mostraban capaces los representantes del despotismo ilustrado, Diderot se encontraba a la vez liberado de las inhibiciones anteriores, bien sea como director de la Enciclopedia, bien como colaborador de la Correspondencia literaria, bien por fin como interlocutor inmediato de Catalina II. Es cierto que Raynal y sus colaboradores se dirigían a los gobernantes del mundo, pero a la vez se dirigían también a todos los pueblos, a cuya ilustración deben contribuir los filósofos por doquier: "Sabios de la tierra, filósofos de todas las naciones, sólo a vosotros os compete elaborar leyes, mostrándolas a vuestros conciudadanos. Tened el coraje de ilustrar a vuestros hermanos" 44 . En realidad, en este horizonte ya no se trataba tanto para Diderot de que el filósofo hablara de lejos a los soberanos o a los pueblos, sino que el problema ahora parece consistir más bien en ponerse del lado del pueblo para desde alli hablar en su nombre a los 
soberanos. La crítica habitual del despotismo a lo largo de los textos de los años setenta experimenta ahora un ensanchamiento. Si hasta ahora su atención había estado dirigida hacia el despotismo en el interior, el colonialismo nos muestra la otra cara del problema, el despotismo hacia fuera. El Diderot interesado en establecer un diálogo con el Poder se inserta así en la historia del anticolonialismo.

\section{Diderot como interlocutor de Séneca}

Todavía va a volver Diderot a pronunciarse, una última vez, sobre el problema de las relaciones entre la Filosofia y el Poder, en un escrito al que cabe sin duda considerar como su testamento filosófico-político. Se trata de su meditación final sobre Séneca, aquel filósofo que no vivió recluido en sus meditaciones sino que trató de orientar al Poder. Se establece así, una vez más, un diálogo entre los protagonistas de la Ilustración y los grandes representantes de la Antigüedad clásica, siendo precisamente Diderot uno de los protagonistas más destacados de este diálogo. Aparte de ser una constante a lo largo de su vida y su obra, en la que jugó a identificarse con figuras prototípicas del pensamiento antiguo como Sócrates y Diógenes, ahora al final de su vida va a reivindicar especialmente la figura de Séneca, como una especie de alter ego con el que poder identificarse. De aquí una vez más la complejidad del pensamiento de Diderot. Por una parte la modernidad es uno de los rasgos tópicos del director de la Enciclopedia. Por otra, destaca en la prosecución del diálogo iniciado en el Renacimiento con la Antigüedad clásica. El descontento con el tiempo presente, señala en una oportunidad, hace que "no nos desagrade este retorno a los tiempos antiguos" 45 .

La ocasión inmediata para esta confrontación con el filósofo estoico se la ofrecieron d'Holbach y Naigeon cuando después de haber concluido la traducción de las obras filosóficas de Séneca, confiada a La Grange, solicitaron a Diderot que escribiera una Vida de Séneca, a modo de complemento idóneo de la nueva edición. Diderot consideró tal encargo como einfinitamente" grato a su corazón. Como resultado de ello va a redactar su apasionado Ensayo sobre la vida de Séneca el fillosofo, sobre sus escritos, y sobre los reinados de Claudio y Nerón (1778). Más adelante, en 1782, aparecerá una segunda edición, considerablemente ampliada, en la que trata de responder a las críticas recibidas.

45 O.C., X, 506. 
Diderot es consciente de que se aproxima a su fin. Sabe que se encuentra "bastante cercano al término en que todo se desvanece" y quiere detenerse un momento a meditar sobre el sentido de su vida, sobre el del movimiento ilustrado, sobre el juicio que en definitiva le merece el compromiso del filósofo con la Ciudad 46. Diderot que vivió profundamente el problema de la posteridad, ese "más allá» del filósofo, según va a escribir a Falconet, que se preocupa por la imagen que de él pervivirá en las generaciones futuras, va a situar esas reflexiones finales en el horizonte de una vida que concluye: «Sólo se piensa, sólo se habla con fuerza desde el fondo de la tumba». Es desde esa perspectiva desde la que quiere dirigirse por última vez a sus coetáneos.

Aun cuando Diderot se ha molestado en documentarse a fondo sobre Séneca, consultando y utilizando ampliamente tanto las fuentes como la bibliografia secundaria, el valor de su estudio no es tanto de carácter erudito y filológico sino más bien autobiográfico y polémico ${ }^{47}$. Desea reivindicar sin duda la figura de Séneca, sobre la que desde antiguo se habían vertido críticas acerca de su actuación ante el Poder. El mismo Diderot en su juventud se había asomado a esa tradición crítica, algo que va a lamentar en su madurez, achacando sus críticas iniciales a un conocimiento insuficiente y a una actitud precipitada. Ahora va a señalar por el contario: «Ah, ¡si hubiera leído más tempranamente las obras de Séneca, si me hubiera imbuido de sus principios a los treinta años, cuántos placeres habría debido a este filósofo, o más bien cuántas penas me habría ahorrado!» 48 . La meditación sobre Séneca tiene un valor autobiográfico al producirse una especie de ósmosis espiritual entre el filósofo romano y el ilustrado, apareciendo Séneca como el alter ego del último Diderot. De ahí ese constante ir y venir de Roma a París y de París a Roma, de los emperadores romanos a los soberanos del siglo XviI y viceversa, y en definitiva de Diderot a Séneca y de Séneca a Diderot. No en vano señala al comienzo del ensayo que: «es tanto mi alma lo que pinto como la de los diferentes personajes que aparecen en mi relato" ${ }^{49}$. Es más, es sobre todo su "alma» lo que Diderot quiere poner en claro en esa especie de testamento. Justificando a Séneca se justifica también a sí mismo. Séneca vendría a ser, en palabras de Diderot, el filósofo «detrás del que me oculto».

46 O.C., III, 9.

47 Cfr. P. CasINI, «Diderot apologiste de Séneque”, en Dix-huitieme siecle, n. 11, 1979, 238 ss.

48 O.C. III, 371.

49 Ibid., 10. 
No es necesariamente que Diderot tenga sentimientos de culpabilidad acerca de los compromisos políticos que fue asumiendo a lo largo de su vida, aunque sí innegables decepciones por los espejismos sufridos, por las inercias y resistencias del Poder a la hora de dejarse permeabilizar por los nuevos principios filosóficos. Su imagen pública no había salido precisamente beneficiada de su relación con Catalina II. Además era más o menos inminente la publicación de otro gran "testamento", las Confesiones de Rousseau, su antiguo hermano-enemigo que, a diferencia de Diderot, había optado por el «exilio interior" frente a una sociedad por la que no se sentía comprendido. A Diderot también le preocupaba la visión que de él pudiera ofrecer Rousseau. Teniendo todo ello en cuenta se comprende que su meditación final sobre Séneca a la vez que pretendía ser una apología del filósofo romano, en última instancia constituyera una apología pro vita sua. Después de todo, el grado de compromiso con el Poder en el caso de Diderot estaba lejos de alcanzar la dimensión dramática del de Séneca, con un déspota absoluto 50 .

Dentro de las consabidas ambigüedades y vacilaciones del estoicismo respecto al compromiso político, también los estoicos romanos se plantearon la cuestión: Sitne sapientis ad rem publicam accedere? Séneca supuso un caso paradigmático dentro de la corriente estoica en que el filósofo optó por partcipar en la res publica. De la forma concreta en que tal participación se llevó a cabo, del grado de contemporización con el ejercicio tiránico del Poder a que haya podido llegar, van a brotar las sombras que persiguen la recepción de Séneca a lo largo de la historia, a las que el Diderot maduro va a tratar de enfrentarse. $i$ Estamos ante un caso de complicidad del sabio con el Poder o, en todo caso, de una contemporización excesiva con el mismo, que resultara éticamente reprobable? El mismo Diderot, en su visión idealizada del filósofo antiguo, no puede obviar la pregunta acerca de qué hacía un filósofo como Séneca en el «antro de la bestia" "51. Dentro de su imagen idealizada, Diderot es bien consciente de que se trata de una situación límite en el problema que le ocupa, pero en su esfuerzo apologético intenta transmutar el objeto tradicional de crítica al filósofo romano en algo a su favor. Séneca, argumenta Diderot, opta por intervenir en politica con vistas a cambiar un sistema corrupto y ser útil a sus conciudadanos. $Y$ si no puede hacer el bien que desea, al menos ha sido capaz con su presencia de evitar males mayores. Ello sería suficiente para considerar a Séneca como el re-

so D. Diderot, Oeuvres complétes, $X X V$, ed. Dieckemann-Varloot, 3 ss.

51 O.C. III, 64-65. 
ferente cualificado de la Antigüedad clásica en cuanto filósofo comprometido y para preferir, a pesar de todas sus vacilaciones, identificarse con Séneca frente al otro gran referente de los ilustrados, que era Sócrates, y con cuya figura, más allá de todos los conflictos, parecía identificarse más Rousseau.

La meditación de Diderot es, en efecto, un alegato a favor del compromiso del sabio con la Ciudad. ¿Para qué sirve la filosofia si guarda silencio?, se pregunta, optando claramente por una filosofía comprometida, militante. Pero para el ilustrado Diderot no basta con que el sabio denuncie los males del mundo en que vive, convirtiéndose en algo así como en su conciencia moral. Diderot da un paso más. El magisterio filosófico tiene para él, ciertamente, un alcance universal y un auténtico filósofo es un ser estimable dondequiera que se encuentre. Pero si la imagen del filósofo es acreedora de un reconocimiento universal, Diderot estima que todavía lo es más si es capaz de desplegar su actividad en el Senado en vez de limitarse a la Escuela, en un Tribunal en vez de quedarse recluido en una Biblioteca ${ }^{52}$. El viejo Diderot, a pesar de sus decepciones, sigue ejerciendo de impenitente ilustrado. Un escrito coetáneo como es la Carta apologética del abate Raynal al señor Grimm (1781) no hace más que confirmar este punto.

No es que Diderot alcance la lucidez y profundidad de la meditación kantiana, pero en todo caso insiste en que tal compromiso no se ha de realizar a expensas de la conciencia moral. Diderot sigue subrayando la doble vertiente de su concepción del filósofo: la teórica y la moral. Sólo ha de ser considerado considerado como filósofo quien se ejercite constantemente en la búsqueda de la verdad y en la práctica de la virtud. Tarea harto dificil de por si, pero todavía más si uno queda apresado en las redes del Poder. Se trataría entonces del intelectual domesticado, reducido a la condición de cortesano. Es algo que Diderot no quiso ser a pesar de su difícil equilibrio entre el compromiso y la independencia del intelectual. En este sentido el viejo Diderot no vacila en criticar las actitudes demasiado contemporizadoras ante el Poder de su antiguo amigo Grimm, otro interlocutor de Catalina II. Cuando en la Carta apologética del abate Raynal reprocha a Grimm haberse reducido a ula triste condición de servidor de los Grandes" 53 , está manifestando toda la distancia que cree que les separa. Con lúcido realismo se refiere en su ensayo sobre Séneca al duro dilema en que se encuentra quien quiere mantener su dignidad en una corte disoluta:

52 O.C. III, 338.

53 D. Diderot, Oeuvres philosophiques, ed. P. Vernière, París, 1964, 631. 
o bien el propio envilecimiento y autodesprecio o bien granjearse el odio de su protector. De haber estado con vida, la reacción de Catalina II ante las apreciaciones críticas manifestadas a su Instrucción, le hubiera recordado amargamente la persistencia de tal dilema.

En definitiva, la confrontación con Séneca le ayuda a comprenderse mejor a sí mismo y al mundo que le rodea. vislumbra preocupantes paralelismos entre su época y la que correspondió vivir a su interlocutor romano: "La convergencia entre nuestras costumbres y las de su época es a veces tan singular, que es preciso ir de la traducción al original para cerciorarse de ello" 54 . El París del Antiguo Régimen, con su corrupción, aparecía como paralelo de la antigua Roma. De la misma manera, los modernos monarcas se le presentaban en su paralelismo con los emperadores romanos. En Diderot está pesando sin duda su experiencia del despotismo ilustrado. sin embargo no necesitaba buscar los paralelismos demasiado lejos cuando tan próxima le resultaba la experiencia francesa. Sin duda Malesherbes, Turgot, Necker podían ser considerados algo así como los modernos Sénecas, pero fueron más bien la excepción, en un horizonte en el que la cúspide del Poder político vegeta en la corrupción y se muestra impermeable a los principios de las Luces. Y paralelismo, por último, entre los adversarios de Séneca y los enemigos del movimiento ilustrado: "Es preciso convenir que los enemigos de nuestros filósofos se asemejan llamativamente a los detractores de Séneca" "55. El movimiento ilustrado no sólo tenía que hacer frente al Poder político y a la Iglesia sino también a los modernos "Aristófanes" como Palissot, Chameix y otros que, aunque desprovistos de su brillantez, se mostraban tan descalificadores como el antiguo.

En diálogo con Séneca, el viejo Diderot sigue defendiendo el compromiso del intelectual con la Ciudad, a pesar de todas las decepciones recibidas, a pesar del carácter mostrenco de la realidad, a pesar de los conflictos que genera la distancia entre la conciencia subjetiva del sabio y las exigencias de la intervención en la sociedad, a pesar de la constatación melancólica de la distancia que separa los ideales de los logros prácticos. Pero en todo caso, el viejo Diderot sigue manteniendo su fidelidad al legado ilustrado, por más que sus concepciones se hayan vuelto más sobrias y realistas ${ }^{56}$. El influjo sobre la opinión pública había seguido una marcha ascendente desde la experiencia de Vincennes y el

\footnotetext{
54 O.C. III, 258.

55 O.C. III, 179.

56 Cfr. P. CasinI, op. cit., 242.
} 
mismo Poder no le envía de nuevo a la prisión a pesar de las alusiones de que era objeto en el ensayo sobre Séneca. Ya se había llevado a cabo en buena medida aquella revolución de los espíritus a que alude Hegel en la Fenomenología. A los pocos años de la muerte de Diderot, los revolucionarios van a hacer trasladar solemnemente los restos de Voltaire y de Rousseau al Panteón. Se reconocía así que la Revolución, a la hora de transformar la estructura del Poder, se sentía heredera del combate filosófico librado a lo largo del siglo, por muy ajenos que fueran los filosofos al desenlace revolucionario. De una forma imprevista, la "posteridad", a que se refería Diderot, estaba rindiendo homenaje a la filosofía militante de la Ilustración, que había irrumpido con decisión en la escena histórica, con todas sus grandezas y servidumbres, con su impronta en la marcha de la historia y también con sus ilusiones y espejismos. 